\title{
Global Impact of Local Educational Innovation
}

\author{
María Luisa Sein-Echaluce ${ }^{1(\bowtie)}(\mathbb{D})$, Ángel Fidalgo-Blanco ${ }^{2}$ (D), \\ Francisco J. García-Peñalvo $^{3(\bowtie)}(\mathbb{D})$, and Ana María Balbín ${ }^{4}(\mathbb{D}$ \\ ${ }^{1}$ Department of Applied Mathematics, University of Zaragoza, Saragossa, Spain \\ mlsein@unizar.es \\ ${ }^{2}$ LITI Laboratory, Technical University of Madrid, Madrid, Spain \\ angel. fidalgo@upm.es \\ ${ }^{3}$ GRIAL Research Group, University of Salamanca, Salamanca, Spain \\ fgarcia@usal.es \\ ${ }^{4}$ Management School, Pontifical Catholic University of Peru, Lima, Peru \\ abalbin@pucp.edu.pe
}

\begin{abstract}
The innovation is carried out according to the demands or needs of an industrial, social or economic sector and is aimed at the widest possible target audience. In teaching educational innovation, the demand for innovation is very local, it is generated in each subject and for the students of it. This causes that educational innovation cannot be easily transferred between subjects. But, to meet the demands of an educational sector, the target audience for which innovation is designed must be global. The objective of this work is to study whether teaching educational innovation can be considered globally (for a global target audience and for a need in the education sector), so that it can be applied and transferred between subjects from different contexts. The information provided, during 8 training courses, by 130 university professors belonging to 12 different universities has been analyzed. It has been shown that for a given need for improvement (passive habit in students), the profile of the target audience, the demand of the learning sector and the indicators to measure educational innovation can be raised in a common way for an entire educational sector; in this case, higher education. The conclusion is that educational innovation can be designed globally, applied locally and transferred to other contexts.
\end{abstract}

Keywords: Educational innovation - Active learning · Innovation indicators · MAIN method

\section{Introduction}

For decades, the innovation, in the industrial sector innovation has been widely recognized as a key factor in improving the competitiveness of companies [1]. Due to the importance of the innovation in the industrial sector, standardized systems for innovation management have been developed and they have positive influence in these facts [2]. In addition to the procedures and standards established in the innovation management standards, still it is recognized the need to use knowledge management tools and continuous improvement of innovation, because are also some of the aspects that 
promote such systems. The Organization for Economic Co-operation and Development (OECD) mentions, through the Oslo manual [3], important barriers that can slow down or speed up the innovation: financing, demand from the own innovation sector, the availability of qualified personnel and administrative obstacles.

As described above, it can be affirmed that in the industrial sector its competitive value is recognized. Indicators that promote the innovation have been identified as well as the standard and certifiable procedures for its management.

Educational innovation is the innovation that is applied in the education sector. Depending on the type of the context of application of such innovation, three types are recognized [4]: 1-innovation is carried out in international projects, which have a similar management to the industrial sector (mainly because it is carried out in collaboration with the industry), 2-the institutional innovation, as per for example, the MOOC, which usually pursue common objectives by the different universities and 3 -the educational innovation that is applied in the classroom, which is often called teaching innovation [5].

Educational teaching innovation is one in which teachers innovate in their own subjects [6], trying to improve learning outcomes. But in this context there are no standards for innovation management and the barriers that can curb innovation, defined by the OCDE, they are very accentuated:

- Financing is usually very little or nothing.

- The target audience is the students of a certain subject and, therefore, the demand for innovation is local and very low.

- Innovative teachers need training in pedagogical tools and approaches [7]. Therefore, universities usually offer this type of training. However, since it is not mandatory for teachers to carry out, their training is very heterogeneous.

- The main administrative obstacle is that educational teaching innovation is not a key or determining factor for teachers to obtain accreditation or professional progress.

The barriers that exist for the realization of educational teaching innovation have important consequences, both for the advancement of the innovation itself, and for the impact it produces in the education sector. The main consequences are:

- Difficult transferring educational teaching innovation. When developing educational innovation in a very local scope, with conditions associated with each teacher and without standardized procedures, it is very difficult to transfer innovation between subjects, even if they belong to the same area of knowledge.

- Repetition of innovative experiences both synchronously (in the same period of time) and asynchronously (in different periods of time). Teaching staff usually carry out educational innovation individually, as there is no adequate transfer of innovation, the same processes are often repeated. This produces a huge effort investment by teachers and does not optimize the low economic resources that are invested to carry out innovation.

- Low impact and consequence on the sector. The main consequence of the existence of the mentioned barriers is that educational teaching innovation progresses slowly and does not produce a transformative effect of the educational model. 
Following is a set of proposals that could reduce the consequences of the characteristic constraints of teaching educational innovation:

- Consider the demand for innovation globally, not only thinking about the students of the subject where the innovation is carried out. To make this possible, it must be demonstrated that the profile of the target audience that demands the innovation, is global. This would mean that the target audience ceases to be local scope and, therefore, their teaching staff could collaborate with each other to apply that innovation (since the beneficiary would not only be their own students, but also those of other subjects). In that case, the collaboration would have an impact on the improvement of the training process [8].

- Consider that the improvements achieved in a given subject, through the application of innovation, are global improvements. That is, they affect all subjects of any educational level. This would result in a greater transformative effect, since it could move more rapidly in the innovation itself [9]. For this to be possible, it must be demonstrated that the current situation presents the same problems in different educational fields.

- Consider that any innovation can be transferable and applicable at any educational level. The transfer of innovation is important as it affects the transformation of education itself [10]. This is possible if teaching educational innovation can be measured through global indicators.

In this work an application model is used based on the previous approaches. The model is called MAIN (Method for Applying Innovation in educatioN) and is based on a sequence of phases that include processes so that innovation can be considered globally (for the entire education sector) even if applied locally (in a certain subject) [11].

The mentioned model has been applied, for this work, in the university context for educational innovations whose main objective is to get students to participate actively in learning. The objectives of the work, for the defined educational purpose, are based on proving:

- Objective 1: That the profile of the target audience that demands innovation is global. For this, the characteristics of the students, to whom innovation is directed, must be similar.

- Objective 2: The demand of the sector that has the same need for educational teaching innovation. This must be proved, either that there is a common vision of the need for innovation, or that there is a current problem that would be improved with innovation.

- Objective 3: That there are common measurable indicators that measure the impact of educational teaching innovation in a global way.

The following sections show the theoretical model, the context of conducting the research to submit the results of said research and the conclusions obtained. 


\section{Theoretical Model}

The MAIN method is composed of four phases that allow the design and application of an educational innovation project regardless of the innovation method to be applied, the technology to be used and the area of knowledge where educational innovation you want to apply [12].

Each of the four phases has a full-time sequence and some main objectives. Figure 1 shows the relationship of the phases.

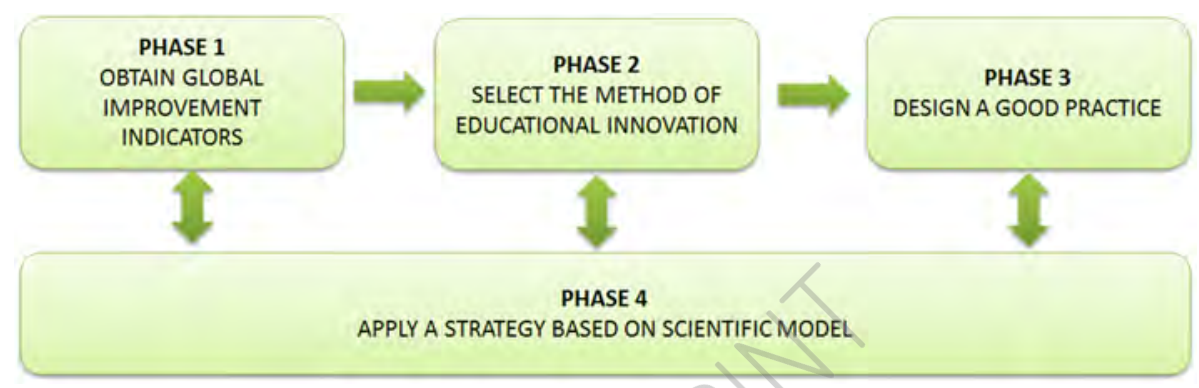

Fig. 1. Name and relationship between the phases of the MAIN method

The main objectives of each phase are:

Phase 1. Obtain global improvement indicators. The professors know the improvements they want to get. These improvements should be measured by indicators that can be common and transferable among the education sector.

Phase 2. Select the method of educational innovation. There are multiple innovation methods that can serve to achieve the same learning achievement [12]. Likewise, there are different technologies that can be used to support each method [13]. In this phase the keys are indicated to choose the method and technology that is most suitable, both to the achievement that is wanted to achieve and to the level of knowledge of the teaching staff (technological, on educational innovation, etc.).

Phase 3. Design a good practice. A good practice of educational innovation must involve a set of indicators based on effectiveness, efficiency, sustainability and transferability [14]. This phase shows how to: get the indicators associated with good practice, plan the activities to be carried out and value the effort required by each activity.

Phase 4. Apply a strategy based on the scientific model. The main objective of this phase is to create and apply educational innovation in such a way that it can be measured and divulge it scientifically.

On the other hand, the MAIN method is totally oriented to the end users of the process; that is, the students and teachers who will use concrete innovation and identify the problems of said end users (phase 1). Based on the problem detected, innovative models are devised and used to solve the problems, providing improvements (phase 2). 
Likewise, a prototype is planned and developed to be used with end users (phase 3). A test and validation of the result is carried out (phase 4). In this sense, the MAIN method can be considered a method based on the principles of "Design Thinking" [15].

In turn, the MAIN method must achieve results quickly, since an educational innovation project applied to a subject is developed and applied during its teaching period. Very often, at the beginning of the project the improvements to be achieved have been identified, but not the most appropriate technologies, processes and methods to be used, therefore, they must be incorporated during the completion of the project. In this sense, the MAIN method can be considered to be an "Agile Method" [16].

This work focuses on phase 1 of the MAIN method, in which three processes are performed sequentially:

- Process P1.1. Obtain the profile of the students that will be the target audience when applying the educational innovation project. It is about obtaining the characteristics presented by the students who present the problem that they want to correct with the project.

- Process P1.2. Identify the negative impact regarding learning that the characteristics identified in the $\mathrm{P} 11$ process have.

- Process P1.3. Find a set of indicators that allow you to measure the improvement you want to obtain.

Processes P1.1, P1.2 and P1.3 correspond to the objectives 1, 2 and 3 of this work. Therefore, the use of phase 1 of the MAIN model is a methodological support to develop this research work. But before starting these processes, it is essential to identify the improvement you want to obtain when applying innovation during the development of a subject. Usually, this improvement has an impact on: an increase in academic results (such as grades obtained), deeper learning, the acquisition of certain skills or an increase in student and teacher satisfaction.

However, the identification of the problem that prevents these improvements or others, can be formulated with different levels of abstraction. Phase 1 of the MAIN method identifies three levels of abstraction, as shown in Fig. 2.

Level 1 is called "sheet problem" and has a low level of generalization. We usually identify a specific problem that occurs in a specific subject. For example, in the subject "Maintenance and safety of vehicles" and in the topic "car engines", a "problematic sheet" would be "to improve the learning of the operation of a combustion engine." The formulation of the problem with this level of generalization is intrinsic to the subject and it is not usually possible to transfer even to similar subjects.

Level 2 is called "branch problem". It is a more generic level than the previous one and it is about identifying global problems that are known to influence improvement, for example, demotivation. The demotivation of students can be caused by various reasons: he does not like the subject, does not have sufficient prior knowledge or it is the teacher himself who demotivates them. The formulation of the problem at this level is global, but if the origin is not identified, it cannot be transferred to other subjects, since this may be different.

Level 3 is called "root problem" It is the most generic problem since it is usually caused by the own educational model from the institution. These are problems that are always present, regardless of the quality of the teaching staff or the nature of the 


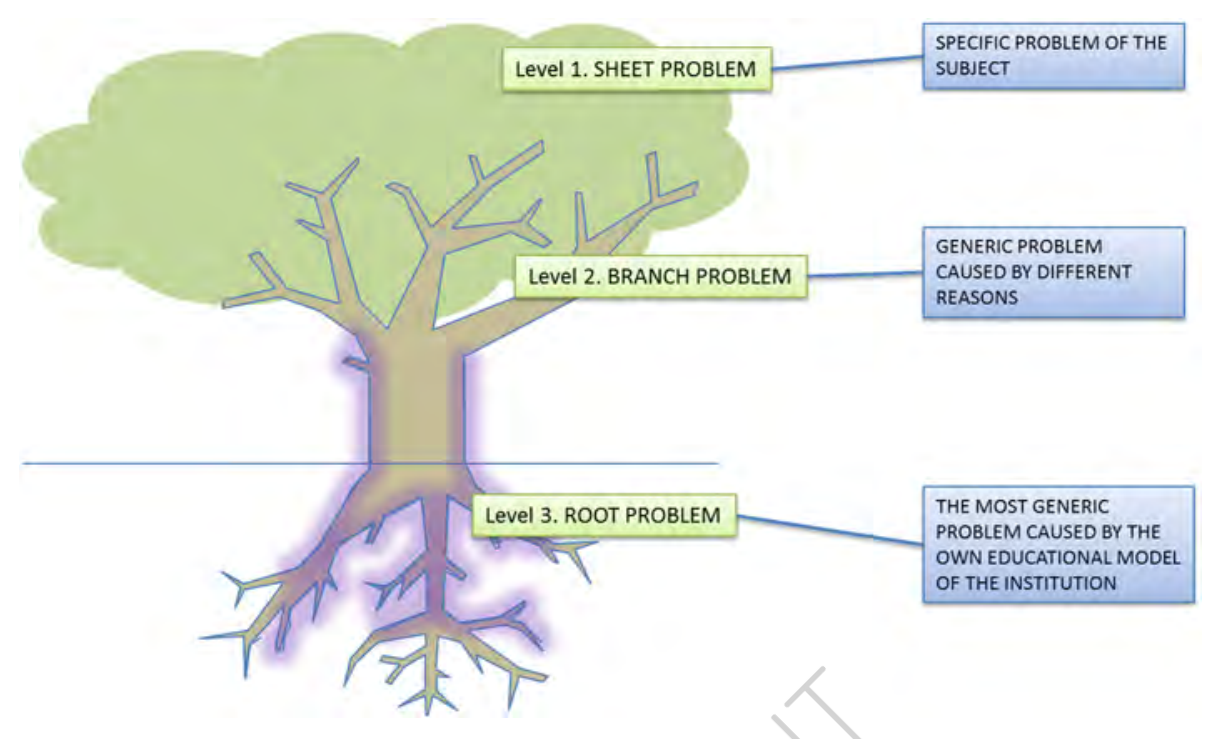

Fig. 2. Different levels of problems

subject. The problem formulated at this level of abstraction can be transferred to any subject that follows an educational model with similar characteristics.

When the level of abstraction to be solved is higher, more global will be the measurable indicators of improvement and, therefore, the result of the innovation will be more transferable. Thus, if phase 1 of the MAIN method is applied to a root problem, global improvement indicators can be achieved from an individual experience, which is the main objective of the work, since it would reduce the current barriers to application and transfer of educational innovation.

\section{Research Context}

This research has been carried out during teacher training courses have taught by the authors during the years 2018, 2019 and 2020 in different universities, and that have been demanded by them within their training plans. In all of them, the main improvement to be obtained was to increase the active participation of students, since the problem with which they worked was the passive habit of students, level 3 (root). The courses, from which the data for this work have been obtained, have been taught at the following universities:

- UNIZAR 1 and UNIZAR 2. University of Zaragoza (public university).

- UVIGO- University of Vigo (public university).

- USJ. University San Jorge (private university).

- USAL- University of Salamanca (public university).

- MMCo- Conference MoodleMoot Colombia 2019. Universities in Colombia, Ecuador, Chile and Mexico (private and public universities). 
- UNA - University of Navarra (private university).

- UPV - University of the Basque Country (public university).

In total 10 universities have participated. Seven Spanish universities (5 public and 2 private) and 4 other universities, from Colombia, Ecuador, Chile and Mexico. The research has been carried out ordering the courses sequentially, following the order of delivery of them, in order to take data in each of them. From now on, each course will be called Session. 132 university professors have participated in all sessions. Table 1 shows the distribution of participants by Session (course).

Table 1. Total number of participants in each session chronologically

\begin{tabular}{l|l|l}
\hline Session-course & Participants & Year \\
\hline Session 1. UNIZAR 1 & 14 & 2018 \\
\hline Session 2. VIGO & 15 & 2018 \\
\hline Session 3. UNIZAR 2 & 15 & 2019 \\
\hline Session 4. USJ & 14 & 2019 \\
\hline Session 5. USAL & 13 & 2019 \\
\hline Session 6. MMco & 19 & 2019 \\
\hline Session 7. UNA & 21 & 2019 \\
\hline Session 8. UPV & 21 & 2020 \\
\hline
\end{tabular}

In these sessions, phase 1 of the MAIN method was applied (Phase 1. Obtain global improvement indicators) and the toolused to obtain the data was the forum, where the participants responded to an open demand. Three forums were used with the following requests to the participants:

- Forum 1. Provide the characteristics of students who present a passive habit.

- Forum 2. Contribute the consequences in the learning process of a passive student.

- Forum 3. Include measurable indicators to verify the impact of the educational innovation to be carried out to solve the root problem (students' passive habit).

The responses of each forum are used to analyze each of the objectives of this work: the forum 1 to analyze the objective 1 (Profile of the target audience that demands innovation is global), the forum 2 to analyze the objective 2 (Demand of the sector which has the same need for educational innovation) and forum 3 to analyze objective 3 (Common measurable indicators that measure the impact of educational innovation on a global basis). In seven sessions, the forums were included in the Moodle elearning platform, used to manage the contents, and in one session the BlackBoard was used.

In next section, the results of the study and the conclusions obtained from it are shown. 


\section{Results}

The results obtained in each forum and session are presented below. For each session, the response types, the number of total responses and the unique responses are analyzed. Overall, for all sessions, the unique responses and the progression of the analysis performed in each session are analyzed. The following subsections will include the analyzes performed for each of the three objectives of the work.

\subsection{Objective 1: Forum 1. Provide Global Characteristics of Passive Students}

The teachers were asked, as a result of their own experience, to indicate aspects of the students that would allow them to intuit that the students are passive.

Table 2 shows for each session (S1 to S8) the number of people who participated in each forum (row 2), the total number of messages provided in the forum (row 3), the number of unique (different) messages in each session (row 4) and the number of global single messages in the investigation, that is, unique messages (different from each other) that have not appeared in the previous sessions (row 5). In the last column the totals of each row are expressed.

Table 2. Participants and messages in forum 1 for each session

\begin{tabular}{lr|r|r|r|r|r|r|r|r}
\hline Forum 1 & S1 & S2 & S3 & S4 & S5 & S6 & S7 & S8 & Totals \\
\hline Participants (PT) & 12 & 15 & 15 & 13 & 15 & 20 & 27 & 19 & 136 \\
\hline Total Messages (MT) & 25 & 44 & 39 & 46 & 34 & 30 & 57 & 52 & 327 \\
\hline Single Messages per Session (MU) & 18 & 16 & 16 & 22 & 21 & 15 & 13 & 16 & 137 \\
\hline Global Single Messages (MUT) & 18 & 5 & 4 & 3 & 2 & 0 & 0 & 0 & 32 \\
\hline
\end{tabular}

In Table 2, 136 professors from at least 8 different universities have given 327 responses (MT), of which 32 have been different. This means that 136 participating teachers (PT) have contributed 32 different characteristics (MUT) that define passive students. Figure 3 shows the evolution of the participants and the messages through the different sessions.

The evolution expressed in Fig. 3 shows that different characteristics are defined in the first sessions, $84 \%$ of the different characteristics are defined in the first three sessions (of 8 sessions). In addition, as of the fifth session, different characteristics are no longer provided, although there are a greater number of participants and responses in these last two sessions.

It is observed that if a greater number of participants (PT), more total responses (MT) are obtained, which is logical. However, the evolution of the different responses (MUT) is independent of the number of participants, since it is observed that it tends to zero. 


\section{Forum 1}

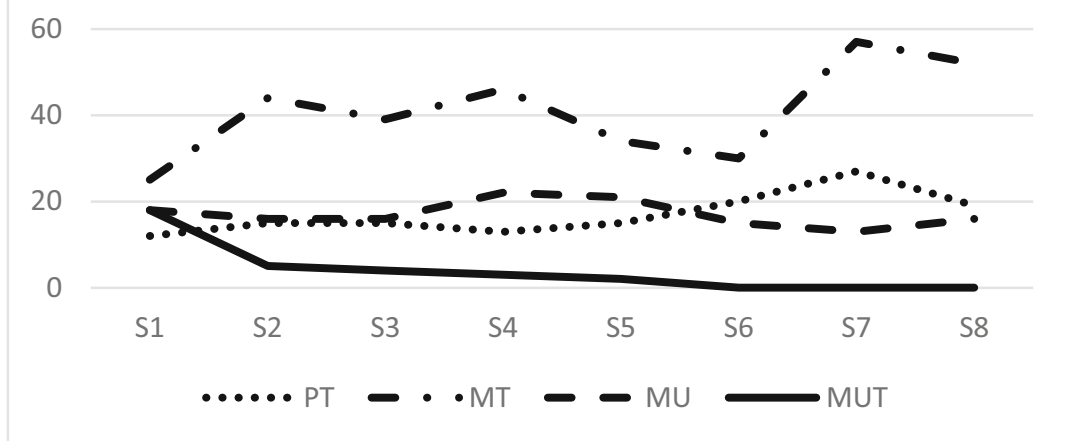

Fig. 3. Evolution of participants and types of messages by sessions in the forum 1

On the other hand, there is a certain stability between the number of different responses per session (MU), being also independent of the number of participants in the session.

The open responses were categorized and the following 5 categories were established:

- AT. Attitude

- PA. Proposed activities

- LK. Learning/Knowledge

- CR. Attitude in the classroom

- TA. Action tutorial

Total responses and total unique responses are grouped by categories, as shown in Table 3. Column 1 represents the category of the classification, column 2 the number of total responses that have been given between all sessions and column three the number of total unique responses.

Table 3. Number of total and unique responses for each category

\begin{tabular}{l|r|l}
\hline Category & Total answers & Global unique responses \\
\hline AT & 106 & 7 \\
\hline PA & 60 & 6 \\
\hline LK & 10 & 5 \\
\hline CR & 145 & 12 \\
\hline TA & 6 & 2 \\
\hline
\end{tabular}

In the analysis, a permanence factor has been established, which measure the presence of a certain different characteristic in all sessions. There are different characteristics that have only been indicated in one or two sessions, so these characteristics 
can not be considered global. On the other hand, there is a set of characteristics that have occurred in at least 7 of the 8 sessions; that is, they have a minimum permanence of $87.5 \%$. These characteristics can be considered global.

Analyzing the unique answers, organized by categories, which have been obtained in at least 7 of the 8 sessions, Table 4 is obtained. The first column represents the category of the question, the second column is the characteristic expressed by the teaching staff and the third column is the percentage of sessions where the same response was obtained (100\% indicates that this response has been given in all sessions and $87.5 \%$ has been given in 7 of the 8 sessions).

Table 4. Number of unique responses in at least 7 of the 8 sessions

\begin{tabular}{l|l|l}
\hline Category & Characteristic & $\%$ \\
\hline AT & Easily mislead in class (look at the mobile, lost look, etc.) & 100 \\
& He has no interest in the subject & 100 \\
\hline PA & Does not participate in proposed individual and group activities & 100 \\
\hline CR & Does not participate in proposed activities in class & 100 \\
& Does not answer the questions & 100 \\
& Does not ask questions & 87.5 \\
& Does not take notes & 87.5 \\
\hline
\end{tabular}

Of the five categories (AT, PA, LK, CR and TA) established, the most different and global responses accumulate are the AT, PA and CR categories (AT. Attitude, PA. Proposed activities and CR. Attitude in the classroom).

\subsection{Objective 2: Forum 2. Contribute Consequences in the Learning Process of a Passive Student}

In this forum, teachers were asked to indicate, from their experience, the impact that the student's passive habit has in the context of learning the subject under investigation.

Table 5 shows, for each session (S1 to S8), the number of people who participated in each forum (row 2), the total number of messages contributed in the forum (row 3), the number of unique messages (row 4) and the number of global single messages in the investigation (row 5). The last column includes the totals of each row. And Fig. 4 shows the evolution of these participants and types of messages.

As Table 5 shows, 135 participants (PT) have provided 299 responses (MT), of which 26 are globally different (MUT). In the first two sessions, 77\% of the different responses have been obtained and as of the fifth session no new one has been contributed, although more people have participated in these sessions.

Thus, as shown in Fig. 4, there is a convergence in teachers' opinions about the impact of passive activity on learning. In the same figure it can be seen that the answers provided are related to the number of participants in each session. However, the number of different responses per session and overall does not keep that relationship. The differences per session are similar. 
Table 5. Participants and messages in forum 2 for each session

\begin{tabular}{l|r|r|r|r|r|r|r|r|c}
\hline Forum 2 & S1 & S2 & S3 & S4 & S5 & S6 & S7 & S8 & Totals \\
\hline Participants (PT) & 12 & 15 & 15 & 14 & 13 & 19 & 26 & 21 & 135 \\
\hline Total Messages (MT) & 19 & 32 & 28 & 37 & 31 & 44 & 56 & 52 & 299 \\
\hline Single Messages per Session (MU) & 11 & 16 & 10 & 14 & 15 & 20 & 11 & 16 & 113 \\
\hline Global Single Messages (MUT) & 11 & 9 & 2 & 3 & 1 & 0 & 0 & 0 & 26 \\
\hline
\end{tabular}

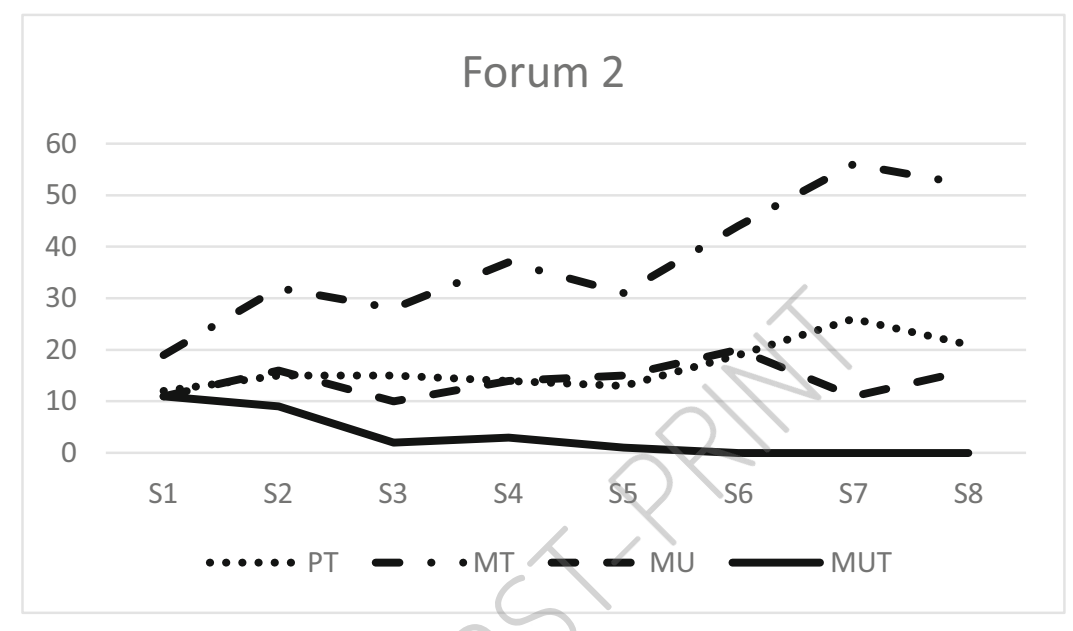

Fig. 4. Evolution of message types by sessions in forum 2

Total open responses and total unique responses are grouped by the aforementioned categories (AT. Attitude, PA. Proposed activities, LK. Learning/Knowledge, CR. Attitude in the classroom, TA. Tutorial action), as shown in the Table 6.

Table 6. Number of total and unique responses for each category

\begin{tabular}{l|c|c}
\hline Category & Total answers & Global unique responses \\
\hline AT & 57 & 6 \\
\hline PA & 12 & 2 \\
\hline LK & 123 & 10 \\
\hline CR & 102 & 6 \\
\hline TA & 5 & 2 \\
\hline
\end{tabular}


Table 7 shows the analysis of unique responses obtained in at least 7 of the 8 sessions. For each category the characteristic included in the messages by the teaching staff is included and the percentage of sessions where that characteristic has appeared (100\% if the characteristic appears in all sessions and $87.5 \%$ if it has appeared in 7 of the 8 sessions).

Table 7. Unique responses appeared in at least 7 of the 8 sessions

\begin{tabular}{l|l|l}
\hline Category & Characteristic & $\%$ \\
\hline AT & Lack of interest in the subject & 87.5 \\
& Lack of motivation & 87.5 \\
\hline \multirow{2}{*}{ LK } & There is no Deep Learning and there is great volatility of content & 87.5 \\
& It is necessary to increase the effort and reinforcement for your learning & 87.5 \\
\hline CR & It infects assets & 87.5 \\
& Desmotiva al profesorado & 87.5 \\
\hline
\end{tabular}

In this forum 2, the different global responses have been more numerous in the AT categories. Attitude, LK. Learning/Knowledge and CR. Attitude in the classroom, and correspond to a permanence factor greater than or equal to $87.5 \%$ in the sessions.

\subsection{Objective 3. Forum 3. Include Measurable Indicators to Verify the Impact of the Educational Innovation to Be Carried Out to Solve the Root Problem (Students' Passive Habit)}

The objective of this analysis is to obtain measurable indicators that allow measuring the impact of any innovation in reducing the passive habit of students. The teachers were asked, as a result of their experience, to indicate which indicators could help them to measure the improvement in their own subjects.

Table 8 shows for each session (S1 to S8) the number of people who participated in each forum (row 2), the total number of messages contributed in the forum (row 3), the number of different messages in the session (row 4) and the number of global single messages in the investigation (row 5). In the last column the totals of each row are expressed. Figure 5 shows the graphical evolution of the total quantities in Table 8.

Table 8. Participants in forum 3 for each session

\begin{tabular}{l|r|r|r|r|r|r|r|r|c}
\hline Forum 3 & S1 & S2 & S3 & S4 & S5 & S6 & S7 & S8 & Totals \\
\hline Participants (PT) & 12 & 14 & 15 & 14 & 14 & 19 & 22 & 20 & 130 \\
\hline Total Messages (MT) & 17 & 60 & 36 & 46 & 55 & 75 & 68 & 67 & 424 \\
\hline Single Messages per Session (MU) & 10 & 25 & 19 & 21 & 20 & 25 & 16 & 15 & 151 \\
\hline Global Single Messages (MUT) & 10 & 19 & 3 & 2 & 0 & 0 & 0 & 0 & 34 \\
\hline
\end{tabular}




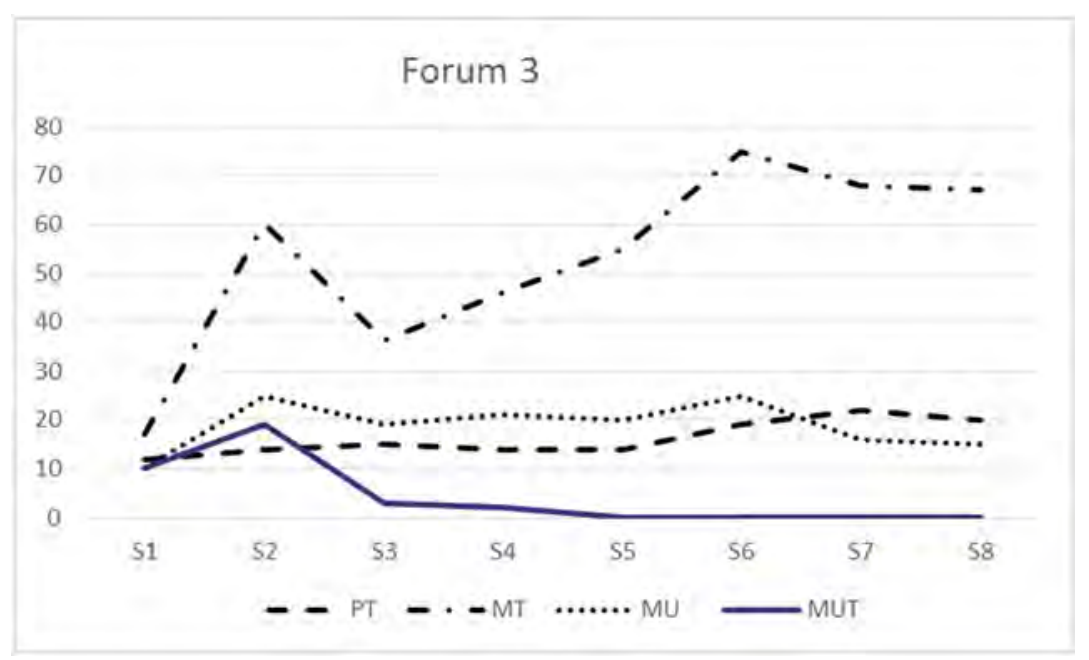

Fig. 5. Evolution of message types by sessions in the forum 3

Table 8 shows that 130 participants (PT) have generated 424 responses (MT) of which 34 have been different (MUT). In the first two sessions, 85\% of the different responses have been provided and as of the fourth session, they have not contributed any.

The graph in Fig. 5 shows that the total different responses are not related to the number of participants and that it tends to zero as the sessions progress. The number of different responses per session (MU) has stability in the sessions and does not depend on the number of participants.

The open answers, as in the previous section, correspond to the same 5 categories (AT. Attitude, PA. Proposed activities, LK. Learning/Knowledge, CR. Attitude in the classroom, TA. Tutorial action). Total responses and global single responses are grouped by categories, as shown in Table 9.

Table 9. Number of total and unique responses for each category

\begin{tabular}{l|c|c}
\hline Category & Total answers & Global unique responses \\
\hline AT & 91 & 7 \\
\hline PA & 80 & 5 \\
\hline LK & 121 & 16 \\
\hline CR & 137 & 5 \\
\hline TA & 17 & 1 \\
\hline
\end{tabular}

Analyzing the number of unique responses that have been obtained in at least 7 of the 8 sessions, Table 10 is obtained, with the category of the response, the characteristic expressed by the teaching staff and the percentage of sessions where the same 
response has been obtained $(100 \%$ indicate that this response has been given in all sessions and $87.5 \%$ has been given in 7 of the 8 sessions).

Table 10. Number of unique responses in at least 7 of the 8 sessions

\begin{tabular}{l|l|l}
\hline Category & Characteristic & $\%$ \\
\hline PA & Students create knowledge and share it & 87.5 \\
& Greater participation in activities that do not influence the grade & 87.5 \\
\hline \multirow{2}{*}{ KK } & Teachers change roles (coordination, advice and facilitator) & 87.5 \\
& The teacher evaluation survey improves & 87.5 \\
\hline \multirow{2}{*}{ CR } & Greater class attendance without being mandatory & 87.5 \\
& Greater participation in class activities (questions, forums, answers) & 100 \\
\hline
\end{tabular}

Similarly, the responses have been grouped into the same previous categories, being more numerous (both in number of responses and in different responses) in the PA categories. Proposed activities, LK. Learning/Knowledge and CR. Attitude in the classroom).

\section{Conclusions}

The work has been based on the problematic root "passive students", which is very common and frequent in the university system. All the teachers from whom the data from this study have been obtained participated in the training courses to try to alleviate this problem.

The main objective of this research work is to demonstrate that, although there is an innovation by and for a given subject, it can be designed in a global way to serve any other subject of the same educational sector, for example, for the sector "college". For this, three objectives were raised:

- Demonstrate that the characteristics of passive students are similar regardless of the university where they study. This would mean that educational innovation can be considered for all passive students, not just that of a certain subject.

- Demonstrate that teachers share a common vision of the impact that student passivity has on their learning. This would mean that there is a real and common need in the educational sector.

- Demonstrate that there is a set of measurable and global indicators to measure the improvement of learning by alleviating the problem of passive student habits. This would mean that the innovation that has managed to improve a root problem can be transferred between subjects that wish to improve that same root problem.

With regard to obtaining characteristics of passive students, the results and interpretation of the messages in forum 1 , it follows that there is a set of common characteristics that define passive students and these characteristics are shared by the teaching staff, since that the global number of different characteristics arises in the first 
sessions of the study ( $83 \%$ in the first three sessions), then they are repeated. Therefore, it can be affirmed that there is a common vision of these characteristics.

A coincidence has been detected, in at least 7 of the 8 sessions, in the characteristics that define the passive students (of the categories AT. Attitude, PA. Proposed activities, and CR. Attitude in the classroom). Thus, it can be affirmed that there is a consensus among the participating teachers regarding the characteristics that define the passive students, and are the following:

- Easily mislead in class (look at the phone, have lost eyes, etc.)

- Has no interest in the subject

- Does not participate in proposed individual and group activities

- Does not participate in activities proposed in class

- Does not answer questions

- Does not ask questions

- Does not take notes

Regarding the second objective, analyze characteristics that allow us to measure the impact of the passive habit of students in their learning, Thus, it can be seen that teachers share a common vision regarding the impact of student passivity and that in the first two sessions the total global unique characteristics have already been obtained.

The analysis of the answers gives the same classification as in the previous section. Total and different responses have been more numerous in AT, LK and CR (AT. Attitude, LK. Learning/Knowledge and CR, Attitude in the classroom). If we take a permanence factor greater than or equal to $87.5 \%$, the impact on learning is:

- Lack of interest in the subject

- Lack of motivation

- There is no Deep Learning and there is great volatility of content

- It is necessary to increase the effort and reinforcement for your learning

- Students with passive habit transmit their passivity to other students

- Students with passive habits demotivate teachers

Finally, with respect to the third objective, to establish the measurable indicators that allow verifying the impact of educational innovation in the improvement of active habit, it is demonstrated, as in the previous objectives, that there is a global and common vision of the indicators measurable improvement.

After the analysis of permanence above $87.5 \%$, it is observed that the most global common and measurable indicators in forum 3 correspond to the PA categories. Proposed activities, LK. Learning/Knowledge and CR. Attitude in the classroom and are the following:

- Students create knowledge and share it

- Greater participation in activities that do not influence the grade

- Teachers change their rol (coordination, advice and facilitator)

- Improves the teachers survey

- Increased class attendance without being mandatory

- Greater participation in class activities (questions, forums, answers, etc.) 
All the graphs results, for the three forums, show that there is a common vision in the different objectives since the identification of these characteristics does not depend on either the university or the number of participants, but on the sequence of the session. Most of the characteristics are defined in the first sessions and according the advance with new contributions reduced to zero. That convergence to zero of the number of global single messages in each of the forums would be accelerated if the order criteria of the sessions had been different, and not the temporality in the delivery of the respective sessions. As an example, if in forum 3 (Table 8) the session 2 had been placed first, 25 of the 34 unique global responses had already been obtained and 0 would have been reached before reaching the fifth session, as with the current order. This is only to illustrate that the order of the sessions only affects in that sense but that the conclusion is the same in each one of the forums, there is a convergence of teachers when interpreting the problem, its impact and the measurable indicators.

It is concluded, therefore, that although each teacher has thought about their own subject, in different universities and even countries, they all agree on the identification of the characteristics of passive students, the consequences it has on their learning and the measurable indicators. Which shows that although educational innovation is locally done, in the subject context, can be raised globally.

In addition, these characteristics and global indicators, obtained in this work from that consensus, will be very useful for any teacher who wants to propose an educational innovation project to palliate the effect of passive students since they will know how to recognize it, anticipate its impact on their learning and apply the indicators to measure the expected improvement. This will allow to design the educational innovation in a global way, apply it locally and transfer it to other contexts.

The work has been done on the root problem "passive habit" of students. As future work, similar studies are planned for other root problems such as lack of prior knowledge and personalized teaching.

Acknowledgments. This work has been partially funded by the Spanish Government Ministry of Economy and Competitiveness throughout the DEFINES project (Ref. TIN2016-80172-R) and the Educational Innovation Service of the Technical University of Madrid (project Ref IE1920.0601). The authors would like to thank the research groups EtnoEdu (https:// socioconstructivismo.unizar.es/), GRIAL (http://grial.usal.es) and LITI (http://www.liti.es) for their support.

\section{References}

1. Roberts, R.: Managing innovation: the pursuit of competitive advantage and the design of innovation intense environments. Res. Policy 27(2), 159-175 (1998)

2. Mir, M., Casadesús, M., Petnji, L.H.: The impact of standardized innovation management systems on innovation capability and business performance: an empirical study. J. Eng. Technol. Manage. - JET-M 41, 26-44 (2016)

3. OECD: Oslo Manual 2018, 4th edn. OECD, Paris (2018)

4. Fidalgo-Blanco, Á.: Últimas tendencias en innovación docente ¿cómo aplicarlas en el aula? IX Jornada Universitaria de Innovación y Calidad. Universidad de Deusto, November-2019. https://zenodo.org/record/3554296\#.XfzxP1VKiUk 
5. Fidalgo-Blanco, Á., Sein-Echaluce, M.L., García-Peñalvo, F.: Tendencias de Innovación Educativa. Algo más que un desfile de moda. In: Conferencia Internacional en Tendencias de Innovación Educativa. CITIE II, (2018)

6. Fidalgo-Blanco, Á., Sein-Echaluce, M.L., García-Peñalvo, F.: ¿Pueden las tendencias de innovación educativa predecir los cambios que transformarán el modelo educativo? 08 May 2019. https://zenodo.org/record/2672967\#.XRU4UugzaU1

7. Cruz-Rojas, G.A., Molina-Blandón, M.A., Valdiri-Vinasco, V.: Vigilancia tecnológica para la innovación educativa en el uso de bases de datos y plataformas de gestión de aprendizaje en la universidad del Valle, Colombia, REVISTA DE INVESTIGACIÓN, DESAR ROLLO E INNOVACIÓN, vol. 9, no. 2, February 2019

8. Bell, T., Urhahne, D., Schanze, S., Ploetzner, R.: Collaborative inquiry learning: models, tools, and challenges. Int. J. Sci. Educ. 32(3), 349-377 (2010)

9. Sein-Echaluce, M., Fidalgo-Blanco, Á., García-Peñalvo, F.J.: Diseño de un proyecto de innovación educativa docente a partir de indicadores transferibles entre distintos contextos, 1st edn. Servicio de Publicaciones Universidad de Zaragoza, Zaragoza (2019)

10. Varpio, L., et al.: Is transferring an educational innovation actually a process of transformation? Adv. Health Sci. Educ. 17(3), 357-367 (2012)

11. Fidalgo-Blanco, Á., Sein-Echaluce, M.L.: Método MAIN para planificar, aplicar y divulgar la innovación educativa. Educ. Knowl. Soc. (EKS) 19(2), 83-101 (2018)

12. Vera, C., Félez, J., Cobos, J.A., Sánchez-Naranjo, M.J., Pinto, G.: Experiences in education innovation: developing tools in support of active learning. Eur. J. Eng. Educ. 31(2), 227-236 (2006)

13. Sánchez-Canales, M., García-Aranda, C., Morillo-Balsera, M.C., Miguel S-de-la-Muela, A., Fernández-GutiérrezdelAlamo, L.: Clasificación de los diferentes modelos de Aula invertida y su aplicación en la Universidad Politécnica de Madrid. In: Aprendizaje, Innovación y Cooperación como impulsores del cambío metodológico. actas CINAIC 2019, pp. 607-611 (2019)

14. Fidalgo-Blanco, Á., Sein-Echaluce Lacleta, M.: ¿Qué hay que hacer para que una innovación educativa se consolide? In: Fores Miravalles, A., Subias Valeccillo, E. (eds.) Pedagogías emergentes : 14 preguntas para el debate, 1st edn. p. 203. Ediciones Octaedro, Barcelona (2018)

15. Fidalgo-Blanco, Á.: Qué es el Design Thinking y su relación con la innovación educativa. Blog Innovación Educativa, MADRID, p. 1 (2019)

16. Fidalgo-Blanco, Á.: Qué son las metodologías ágiles y su aplicación a la innovación educativa. Blog Innovación Educativa, MADRID, p. 1 (2020) 